\title{
Distribution and characteristics of COPD phenotypes - results from the Polish sub-cohort of the POPE study
}

This article was published in the following Dove Press journal: International Journal of COPD

\author{
Aleksander Kania,' Rafał \\ Krenke, ${ }^{2}$ Krzysztof Kuziemski, ${ }^{3}$ \\ Małgorzata Czajkowska- \\ Malinowska, ${ }^{4}$ Natalia \\ Celejewska-Wójcik,' Barbara \\ Kuźnar-Kamińska, ${ }^{5}$ Małgorzata \\ Farnik, ${ }^{6}$ Juliusz Bokiej, ${ }^{7}$ \\ Marta Miszczuk, ${ }^{2}$ Iwona \\ Damps-Konstańska, ${ }^{3}$ Marcin \\ Grabicki, ${ }^{5}$ Marzena Trzaska- \\ Sobczak, ${ }^{6}$ Krzysztof Sładek, \\ Halina Batura-Gabryel, ${ }^{5}$ Adam \\ Barczyk $^{6}$
}

'Department of Pulmonology, II Chair of Internal Medicine, Faculty of Medicine, Jagiellonian University Medical College, Kraków, Poland; '²Department of Internal Medicine, Pulmonary Diseases and Allergy, Medical University of Warsaw, Warsaw, Poland; ${ }^{3}$ Department of Allergology and Pneumonology, Medical University of Gdańsk, Gdańsk, Poland; 'Department of Lung Diseases and Respiratory Failure, Regional Center of Pulmonology, Bydgoszcz, Poland; ${ }^{5}$ Department of Pulmonology, Allergology and Respiratory Oncology, Poznań University of Medical Sciences, Poznań, Poland; 'Department of Pneumology, School of Medicine in Katowice, Medical University of Silesia, Katowice, Poland; ' ${ }^{7}$ epartment of Lung Diseases, Regional Hospital Center Jelenia Góra, Jelenia Góra, Poland

Correspondence: Aleksander Kania Department of Pulmonology, II Chair of Internal Medicine, Faculty of Medicine, Jagiellonian University Medical College, Skawinska 8, 31-066 Kraków, Poland

Tel +48 I2 4305266

Fax +48 I2 4325600

Email aleksanderkania@interia.pl
Background: This study aimed to examine the distribution of predefined phenotypes, demographic data, clinical outcomes, and treatment of patients who were included in the Polish cohort of the Phenotypes of COPD in Central and Eastern Europe (POPE) study.

Patients and methods: This was a sub-analysis of the data from the Polish cohort of the POPE study, an international, multicenter, observational cross-sectional survey of COPD patients in Central and Eastern European countries. The study included patients aged $>40$ years, with a confirmed diagnosis of COPD, and absence of exacerbation for at least 4 weeks before study inclusion. A total of seven Polish centers participated in the study.

Results: Among the 430 Polish COPD patients enrolled in the study, $61.6 \%$ were non-exacerbators (NON-AE), 25.3\% were frequent exacerbators with chronic bronchitis (AE CB), 7.9\% were frequent exacerbators without chronic bronchitis (AE NON-CB), and $5.1 \%$ met the definition of asthma-COPD overlap syndrome (ACOS). There were statistically significant differences among these phenotypes in terms of symptom load, lung function, comorbidities, and treatment. Patients with the AE CB phenotype were most symptomatic with worse lung function, and more frequently reported anxiety and depression. Patients with the ACOS phenotype were significantly younger and were diagnosed with COPD earlier than those with other COPD phenotypes; those with the ACOS phenotype were also more often atopic and obese.

Conclusion: There is significant heterogeneity among COPD patients in the Polish population in terms of phenotype and clinical outcome. The non-exacerbator phenotype is observed most frequently in Poland, while the frequent exacerbator with chronic bronchitis phenotype is the most symptomatic.

Keywords: chronic obstructive pulmonary disease, asthma-COPD overlap syndrome, phenotypes

\section{Introduction}

COPD is characterized by persistent respiratory symptoms and airflow limitation, as a result of airway and/or alveolar abnormalities usually caused by significant exposure to noxious particles or gases. The major risk factor for the development of COPD is tobacco smoking; other risk factors include age, previous history of asthma, respiratory infections, and genetic predisposition, ${ }^{1-6}$ as well as exposure to environmental pollution and smoke from biomass fuels. ${ }^{7,8}$

The idea that COPD is actually one disease instead of two (emphysema and chronic bronchitis) was first formed about 60 years ago. Although many COPD patients present features of both emphysema and chronic bronchitis, there are still patients with a 
significant predominance of either one of these historical phenotypes. Moreover, there has been increased awareness of further heterogeneity among COPD (ie, more possible phenotypes), as reported in a series of new publications. ${ }^{9-11}$ A COPD phenotype can be defined as "a single or combination of disease attributes that describe differences between individuals with COPD as they relate to clinically meaningful outcomes". ${ }^{10}$ In the most recent Spanish guidelines for COPD,${ }^{11}$ the following COPD phenotype classifications were proposed: non-exacerbator, asthma-COPD overlap syndrome (ACOS), exacerbator with emphysema, and exacerbator with chronic bronchitis. However, there is currently no general consensus on the precise number of particular COPD phenotypes that can occur.

According to Miravitlles et al, ${ }^{12}$ the ability to identify a group of COPD subjects who will respond to specific treatment is one of the most important features of "clinically relevant phenotypes". Based on this concept, patients with the infrequent exacerbations phenotype may be treated with bronchodilators alone, ${ }^{13,14}$ while COPD patients with features of asthma (ACOS phenotype) benefit from additional treatment with inhaled corticosteroids (ICS). ${ }^{15}$ Furthermore, roflumilast (a selective inhibitor of phosphodiesterase type 4) has been shown to reduce the number of exacerbations only in COPD patients with chronic bronchitis and frequent exacerbations. ${ }^{16}$ Therefore, understanding of these phenotypes is critical for guiding COPD treatment.

Numerous studies around the world have attempted to identify and estimate the prevalence of COPD phenotypes in various populations, each with slightly differing outcomes. ${ }^{17,18}$ These differences in study outcomes can probably be attributed to the diversity of environmental pollution, smoking prevalence, socioeconomic status, and general health of populations living in particular countries (including European populations) and world regions. Therefore, the objectives of the Phenotypes of COPD in Central and Eastern Europe (POPE) study were to investigate the distribution of different COPD phenotypes, patient characteristics, and treatment patterns of COPD patients in Central and Eastern Europe (CEE) countries. ${ }^{19}$

The current paper focuses on the distribution of phenotypes, demographic data, clinical outcomes, and treatment of patients who were included in the Polish cohort of the POPE study.

\section{Patients and methods}

\section{Study design}

The POPE study was an international, multicenter, observational, cross-sectional survey of COPD patients in CEEcountries
(ClinicalTrials.gov registry identifier: NCT02119494). Poland was among 11 countries participating in the study, with seven centers enrolling subjects. The study was performed in accordance with the ethics principles of the Declaration of Helsinki. The Ethics Committee of the Polish coordinating center (University of Silesia in Katowice) reviewed the study protocol and decided that the study did not need ethical approval due to its non-interventional design. All enrolled patients gave written informed consent to participate in the study.

A complete list of Polish centers participating in the study is given in Table 1. Details of the methodology and recruitment strategy used in the study are described elsewhere. ${ }^{19}$ Briefly, COPD patients were examined in an outpatient setting and had to fulfill the following inclusion criteria: aged more than 40 years, confirmed diagnosis of COPD with post-bronchodilator forced expiratory volume in 1 second $\left(\mathrm{FEV}_{1}\right) /$ forced vital capacity $(\mathrm{FVC})<0.7$, and absence of exacerbation for at least 4 weeks before study inclusion. Only COPD patients with smoking history equal to or more than 10 pack-years were included. Although the inclusion criteria for the POPE cohort involved patients with a smoking history of less than 10 pack-years and pronounced additional exposure to other COPD risk factors, no such individuals were enrolled in the Polish sub-cohort. An electronic case report form was used for data collection. Patients were enrolled between April 2014 and July 2015. Distribution of predefined phenotypes, as well as the association between phenotype and clinical outcomes, was evaluated.

\section{Study cohort characteristics}

The following data were collected for each patient: allergy and atopy status, COPD symptoms (dyspnea at rest/during exercise, fatigue, cough, chronic sputum production, purulent

Table I Polish centers participating in the POPE study

\begin{tabular}{ll}
\hline Number & Centre name \\
\hline I & $\begin{array}{l}\text { Department of Lung Diseases and Respiratory Failure, } \\
\text { Regional Center of Pulmonology, Bydgoszcz }\end{array}$ \\
& $\begin{array}{l}\text { Department of Internal Medicine, Pulmonary Diseases } \\
\text { and Allergy, Medical University of Warsaw, Warsaw }\end{array}$ \\
3 & Department of Allergology and Pneumonology, Medical \\
& University of Gdańsk, Gdańsk \\
& Department of Lung Diseases, Regional Hospital Center, \\
5 & Jelenia Góra \\
& Department of Pulmonology, Allergology and Respiratory \\
& Oncology, Poznań University of Medical Sciences, Poznań \\
7 & Department of Pulmonology, Jagiellonian University \\
& Medical College, Kraków \\
& Kepartment of Pneumology, School of Medicine in \\
\hline
\end{tabular}

Abbreviation: POPE, Phenotypes of COPD in Central and Eastern Europe. 
expectoration), smoking status and other respiratory risk factors, acute respiratory events (including number of COPD exacerbations), concomitant respiratory and non-respiratory diseases, pharmacological and non-pharmacological treatment. Patients were classified into one of four GOLD 2014 categories (A-D) based on the value of the post-bronchodilator $\mathrm{FEV}_{1}$, history of COPD exacerbations, and intensity of respiratory symptoms using the modified Medical Research Council (mMRC) dyspnea scale and the COPD Assessment Test (CAT). ${ }^{1,2,20,21}$

\section{Phenotype definitions}

Patients were divided according to predefined phenotypes. The following algorithm was used to distinguish specific phenotypes among recruited COPD patients: 1) patients with asthma diagnosis before the age of 40 years or a positive bronchodilator test in the previous 12 months with a history of atopy and/or allergy were considered a mixed COPD-asthma phenotype (ACOS), 2) patients with less than two exacerbations in the previous year were classified as the non-exacerbator phenotype (NON-AE), 3) frequent exacerbators reporting chronic cough and expectoration for more than 3 months per year over 2 consecutive years were described as frequent exacerbators with chronic bronchitis $(\mathrm{AE} \mathrm{CB}), 4)$ the remaining frequent exacerbators were classified as frequent exacerbators without chronic bronchitis, predominantly with emphysema (AE NON-CB). ${ }^{19}$

\section{Statistical analysis}

Categorical data were summarized as absolute and relative values, while continuous data were presented as median and 5th-95th percentile. Differences among the groups were analyzed using Kruskal-Wallis test and the Mann-Whitney $U$-test for pairwise comparisons; Fisher exact test was used to assess differences in categorical data. All tests were two-tailed; a $p$-value of $<0.05$ was considered significant. Statistical analyses were performed using SPSS version 22.0.0 (IBM Corporation, Armonk, NY, USA, 2013).

\section{Results Distribution of phenotypes}

A total of 430 patients with COPD were enrolled in the study; all patients were included in the final analysis. The majority of patients $(61.6 \%)$ were classified as the NON-AE phenotype. The AE CB and AE NON-CB phenotypes were observed in $25.3 \%$ and $7.9 \%$ of the study cohort, respectively, and $5.1 \%$ of patients met the definition for the ACOS phenotype (Figure 1).

\section{Characteristics of patients according to phenotypes}

Detailed characteristics of patients with the different COPD phenotypes are summarized in Table 2. The percentage of males was higher in the NON-AE phenotype compared to the $\mathrm{AE}$ NON-CB and AE CB phenotypes. Patients with the ACOS phenotype were significantly younger and their diagnosis of COPD was established earlier than in the other phenotypes; they were also more often atopic and obese than those with the other COPD phenotypes.

Significant differences between the phenotypes were observed in terms of symptoms, CAT and mMRC scores, and airflow limitation (measured as $\mathrm{FEV}_{1} \%$ of predicted). Those with the AE CB phenotype had the most intense symptoms (the highest CAT scores), the poorest tolerance of physical effort, and the most impaired lung function (the lowest $\mathrm{FEV}_{1} \%$ of predicted). In line with these severe symptoms of lung disease, depression and anxiety were most common among AE CB subjects.

The global weight of comorbidities, measured by the Charlson index, was similar among all the groups (Table 3); however, atopy was significantly more common in those with the ACOS phenotype. We also found smoking habits were different among the phenotypes: there were fewer current smokers in the AE CB group compared to the ACOS and NON-AE groups. In addition, those with the AE CB phenotype smoked more cigarettes (measured by pack-years) compared to patients with the ACOS phenotype.
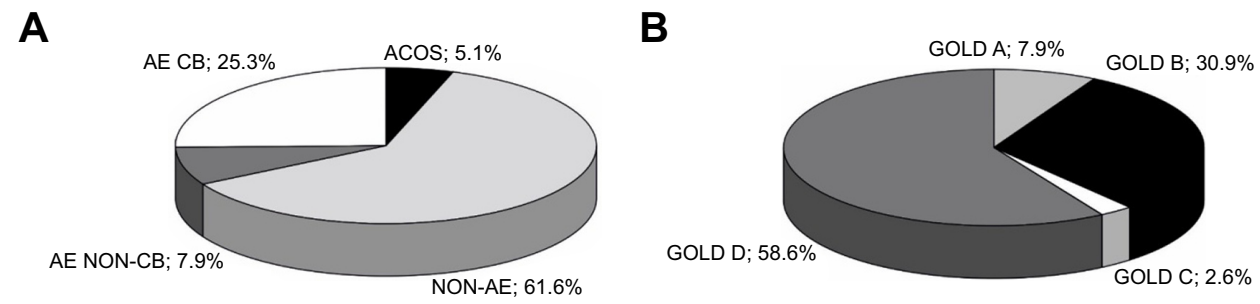

Figure I (A) Distribution of phenotypes and (B) GOLD categories (A-D) in the Polish study cohort.

Abbreviations: ACOS, asthma-COPD overlap syndrome; NON-AE, non-exacerbator; $A E N O N-C B$, exacerbator without chronic bronchitis; $A E$ CB, frequent exacerbator with chronic bronchitis. 
Table 2 Baseline characteristics of patients with different COPD phenotypes

\begin{tabular}{|c|c|c|c|c|c|}
\hline & \multicolumn{5}{|l|}{ Phenotype } \\
\hline & $A \cos (a)$ & NON-AE (b) & AE NON-CB (c) & $\mathrm{AE} \mathrm{CB}^{\#}(\mathrm{~d})$ & $p$-value \\
\hline & $\mathbf{N}=\mathbf{2 2}$ & $\mathbf{N}=\mathbf{2 6 5}$ & $\mathbf{N}=34$ & $\mathrm{~N}=109$ & \\
\hline Number of men (\%) & $13(59.1 \%)$ & $194(73.2 \%)^{c, d}$ & $19(55.9 \%)^{\mathrm{b}}$ & $68(62.4 \%)^{\mathrm{b}}$ & 0.041 \\
\hline Age at inclusion (years) & $59.0(44.0 ; 70.0)^{\mathrm{b}-\mathrm{d}}$ & $67.0(54.0 ; 83.0)^{\mathrm{a}}$ & $68.0(50.0 ; 88.0)^{\mathrm{a}}$ & $68.0(56.0 ; 83.0)^{\mathrm{a}}$ & $<0.001$ \\
\hline Age at COPD diagnosis (years) & $49.5(40.0 ; 60.0)^{\mathrm{b}-\mathrm{d}}$ & $61.0(45.0 ; 75.0)^{\mathrm{a}}$ & $60.0(41.0 ; 75.0)^{\mathrm{a}}$ & $57.0(42.0 ; 73.0)^{\mathrm{a}}$ & $<0.001$ \\
\hline \multicolumn{6}{|l|}{ Area } \\
\hline Urban & 19 (90.5\%) & $188(72.0 \%)$ & $30(88.2 \%)$ & $80(79.2 \%)$ & \multirow[t]{2}{*}{0.049} \\
\hline Rural & $2(9.5 \%)$ & $73(28.0 \%)$ & 4 (II.8\%) & 21 (20.8\%) & \\
\hline \multicolumn{6}{|l|}{ Dyspnea } \\
\hline Exertional & 20 (90.9\%) & $240(90.6 \%)^{d}$ & $32(94.1 \%)$ & $109(100.0 \%)^{b}$ & 0.001 \\
\hline Resting & $4(18.2 \%)$ & $23(8.7 \%)$ & $3(8.8 \%)$ & $16(14.7 \%)$ & 0.191 \\
\hline Cough & $18(81.8 \%)^{c}$ & $190(71.7 \%)^{\mathrm{c}, \mathrm{d}}$ & $14(4 \mid .2 \%)^{\mathrm{a}, \mathrm{b}, \mathrm{d}}$ & $104(95.4 \%)^{\mathrm{b}, \mathrm{c}}$ & $<0.001$ \\
\hline Sputum & $14(63.6 \%)$ & $159(60.0 \%)$ & $0(0 \%)$ & $109(100 \%)$ & $0.823 *$ \\
\hline Fatigue & $10(45.5 \%)$ & $96(36.5 \%)$ & $16(47.1 \%)$ & $43(39.4 \%)$ & 0.560 \\
\hline \multicolumn{6}{|l|}{ Smoking } \\
\hline Ex-smokers & $13(59.1 \%)^{d}$ & $188(70.9 \%)^{d}$ & $28(82.4 \%)$ & $90(82.6 \%)^{a, b}$ & \multirow[t]{2}{*}{0.025} \\
\hline Current smokers & $9(40.9 \%)^{d}$ & $77(29.1 \%)^{d}$ & $6(17.6 \%)$ & $19(17.4 \%)^{\mathrm{a}, \mathrm{b}}$ & \\
\hline Smoking burden (pack-years) & $22.5(14 ; 36)^{d}$ & $38(25 ; 50)$ & $35(24 ; 49)$ & $43(30 ; 56)^{\mathrm{a}}$ & 0.082 \\
\hline BMI $\left(\mathrm{kg} / \mathrm{m}^{2}\right)$ & $29 . I(22.6 ; 4 I .2)^{\mathrm{b}, \mathrm{d}}$ & $27.1(19.8 ; 36.9)^{\mathrm{a}, \mathrm{c}}$ & $28.8(20.6 ; 43.0)^{\mathrm{b}}$ & $27.2(18.3 ; 42.2)^{a}$ & 0.023 \\
\hline $\mathrm{FEV}_{\text {, }}(\%$ predicted $)$ & $59.3(34.5 ; 8 \mathrm{I} .4)^{\mathrm{d}}$ & $55.7(26.8 ; 92.1)^{d}$ & $52.4(28.8 ; 74.0)$ & $42.6(19.5 ; 77.2)^{\mathrm{a}, \mathrm{b}}$ & $<0.001$ \\
\hline FVC (\% predicted) & $83.9(55.1 ; 110.8)$ & $87.2(52.8 ; 123.4)$ & $76.8(49.4 ; 126.5)$ & $79.3(48.5 ; 116.1)$ & 0.166 \\
\hline CAT - total score & $16.0(6.0 ; 33.0)^{d}$ & $18.0(5.0 ; 32.0)^{d}$ & $19.5(6.0 ; 32.0)$ & $24.0(8.0 ; 35.0)^{\mathrm{a}, \mathrm{b}}$ & $<0.001$ \\
\hline \multicolumn{6}{|l|}{$\mathrm{mMRC}$} \\
\hline 0 & $4(18.2 \%)^{d}$ & $23(8.7 \%)^{d}$ & $2(5.9 \%)^{d}$ & $0(0.0 \%)^{a-c}$ & \multirow[t]{5}{*}{$<0.001$} \\
\hline I & $4(18.2 \%)^{d}$ & $77(29.1 \%)^{d}$ & $3(8.8 \%)^{d}$ & $7(6.4 \%)^{a-c}$ & \\
\hline 2 & $11(50.0 \%)^{d}$ & $86(32.5 \%)^{d}$ & $14(41.2 \%)^{\mathrm{d}}$ & $33(30.3 \%)^{a-c}$ & \\
\hline 3 & $2(9.1 \%)^{d}$ & $56(21.1 \%)^{d}$ & $14(4 \mid .2 \%)^{d}$ & $39(35.8 \%)^{a-c}$ & \\
\hline 4 & I $(4.5 \%)^{d}$ & $23(8.7 \%)^{d}$ & I $(2.9 \%)^{d}$ & $30(27.5 \%)^{\mathrm{a}-\mathrm{c}}$ & \\
\hline \multicolumn{6}{|l|}{ GOLD categories } \\
\hline A & $2(9.1 \%)^{d}$ & $32(12.1 \%)^{c, d}$ & $0(0.0 \%)^{b}$ & $0(0.0 \%)^{a, b}$ & \multirow[t]{4}{*}{$<0.001$} \\
\hline B & $8(36.4 \%)^{c, d}$ & $125(47.2 \%)^{c, d}$ & $0(0.0 \%)^{a, b}$ & $0(0.0 \%)^{a, b}$ & \\
\hline $\mathrm{C}$ & $2(9.1 \%)$ & $4(1.5 \%)^{c}$ & $3(8.8 \%)^{b}$ & $2(1.8 \%)$ & \\
\hline D & $10(45.4 \%)^{c, d}$ & $104(39.2 \%)^{c, d}$ & $31(91.2 \%)^{\mathrm{a}, \mathrm{b}}$ & $107(98.2 \%)^{a, b}$ & \\
\hline \multicolumn{6}{|l|}{ Other risk factors } \\
\hline Yes (\%) & $6(27.3 \%)$ & $52(19.6 \%)$ & $2(5.9 \%)$ & $24(22 \%)$ & 0.15 \\
\hline Workplace environment & $5(22.7 \%)$ & $48(18.1 \%)$ & I (2.9\%) & $17(I 5.6 \%)$ & 0.12 \\
\hline Frequent exposure to outdoor & 0 & $2(0.76 \%)$ & 0 & 0 & 0.31 \\
\hline \multicolumn{6}{|l|}{ pollution (eg, organic dusts) } \\
\hline Exposure to indoor pollution & I (4.6\%) & $4(1.5 \%)$ & I (2.9\%) & $4(3.7 \%)$ & 0.54 \\
\hline Cooking fire without ventilation & I (4.6\%) & $4(1.5 \%)$ & 0 & $5(4.6 \%)$ & 0.34 \\
\hline $\begin{array}{l}\text { Total number of exacerbations } \\
\text { (in the last } 12 \text { months) }\end{array}$ & I $(0-2)^{b-d}$ & $0(0-I)^{a, c, d}$ & $2(2-3)^{a, b}$ & $3(2-4)^{a, b}$ & $<0.001$ \\
\hline
\end{tabular}

Notes: Categorical parameters are described by absolute (relative) frequencies, and statistical significance was determined by the Fisher exact test. Indices a- $d$ indicate a statistical significant difference between two phenotypes (Fisher exact test). Continuous parameters are described by median (5th; 95th percentiles) and valid N, and statistical significance was determined by the Kruskal-Wallis test. Indices a-d indicate a statistical significant difference between two phenotypes (pairwise comparisons). *Statistical significance is tested only for ACOS and NON-AE. "According to the classic definition of chronic bronchitis, patients were diagnosed as having this condition if cough occurred every day with sputum production and lasted for $\geq 3$ months for 2 consecutive years. No patients with $A E N O N-C B$ have sputum and all patients with $A E$ $\mathrm{CB}$ have sputum. Bold represent statistically significant values $(p<0.05)$.

Abbreviations: ACOS, asthma-COPD overlap syndrome; NON-AE, non-exacerbator phenotype; AE NON-CB, frequent exacerbators without chronic bronchitis, predominantly with emphysema; AE CB, frequent exacerbators with chronic bronchitis; BMI, body mass index; FEV , forced expiratory volume in I second; FVC, forced vital capacity; CAT, COPD Assessment Test; mMRC, modified Medical Research Council.

There were also differences between treatment regimens among patients with various COPD phenotypes (Table 4). Triple therapy, including long-acting muscarinic antagonists (LAMA), long-acting beta agonists (LABA), and ICS, was most commonly used in patients with the $\mathrm{AE} \mathrm{CB}$ phenotype. Almost twice as many patients with the AE CB phenotype were treated with the LAMA+LABA+ICS combination compared to those with the NON-AE phenotype $(p<0.001)$. 
Table 3 Comorbidities in patients with different COPD phenotypes

\begin{tabular}{|c|c|c|c|c|c|}
\hline & \multicolumn{5}{|l|}{ Phenotype } \\
\hline & $\overline{A C O S}(a)$ & NON-AE (b) & AE NON-CB (c) & AE CB (d) & $p$-value \\
\hline & $\mathbf{N}=\mathbf{2 2}$ & $N=265$ & $\mathbf{N}=34$ & $\mathbf{N}=109$ & \\
\hline Depression & $0(0.0 \%)^{c, d}$ & $16(6.0 \%)^{c}$ & $9(26.5 \%)^{a, b}$ & $17(15.6 \%)^{a, b}$ & $<0.001$ \\
\hline Anxiety & I (4.6\%) & II $(4.2 \%)^{d}$ & $3(8.8 \%)$ & $13(11.9 \%)^{b}$ & 0.044 \\
\hline Insomnia & 2 (9.1\%) & $33(12.5 \%)$ & $3(8.8 \%)$ & 31 (28.4\%) & 0.77 \\
\hline \multirow[t]{2}{*}{ Sleep apnea } & $2(9.1 \%)$ & $32(12.4 \%)$ & $2(6.1 \%)$ & 12 (11.1\%) & 0.73 \\
\hline & $\mathrm{N}=22$ & $\mathrm{~N}=259$ & $\mathrm{~N}=33$ & $\mathrm{~N}=108$ & \\
\hline \multirow[t]{2}{*}{ Bronchiectasis } & $4(3.5 \%)$ & 19 (7.4\%) & $3(9.1 \%)$ & 12 (II.0\%) & 0.27 \\
\hline & $\mathrm{N}=2 \mathrm{I}$ & $\mathrm{N}=257$ & $N=33$ & $\mathrm{~N}=109$ & \\
\hline Charlson & $\mathrm{I}(\mathrm{I} ; 4)$ & $2(1 ; 4)$ & $2(1 ; 6)$ & $2(1 ; 5)$ & 0.15 \\
\hline \multicolumn{6}{|l|}{ comorbidity index } \\
\hline Atopy & $16(72.7 \%)^{b-d}$ & $14(5.3 \%)^{\mathrm{a}}$ & I (2.9\%) & $3(2.8 \%)^{a}$ & $<0.001$ \\
\hline
\end{tabular}

Notes: Categorical parameters are described by absolute (relative) frequencies, and statistical significance was determined by the Fisher exact test. Indices a-d indicate a statistical significant difference between two phenotypes (Fisher exact test). Continuous parameters are described by median (5th; 95 th percentiles) and valid N, and statistical significance was determined by the Kruskal-Wallis test. Indices a-d indicate a statistical significant difference between two phenotypes (pairwise comparisons). Bold represent statistically significant values $(p<0.05)$.

Abbreviations: ACOS, asthma-COPD overlap syndrome; NON-AE, non-exacerbator phenotype; AE NON-CB, frequent exacerbators without chronic bronchitis, predominantly with emphysema; $\mathrm{AE} C B$, frequent exacerbators with chronic bronchitis.

Similarly, treatment with bronchodilators only (one or both) was more frequent in those with the NON-AE phenotype compared to the AE CB phenotype (Table 4).

\section{Discussion}

To the best of our knowledge, this is the first paper presenting the characteristics and relative prevalence of different COPD phenotypes in Poland. In this paper, we reported the distribution, clinical characteristics, and treatment of predefined COPD phenotypes in the Polish cohort of patients recruited in the POPE study. Several reasons stood behind the decision to analyze the Polish sub-cohort of the POPE study.
Among countries participating in the POPE study, Poland's geographical location is the least favorable, with hard coal remaining the main source of energy. This could affect the epidemiology of COPD phenotypes. The distribution of COPD phenotypes varies among countries taking part in the POPE project, ${ }^{22}$ which also provoked the authors to take a deeper look at the situation in Poland.

It should be highlighted that patients were assigned to the four different COPD phenotypes according to a predefined algorithm. ${ }^{19} \mathrm{We}$ found that patients with the frequent exacerbator phenotype constituted one-third of all COPD patients participating in the study. The vast majority of frequent

Table 4 Medications used to treat patients with different COPD phenotypes

\begin{tabular}{|c|c|c|c|c|c|}
\hline & \multicolumn{5}{|l|}{ Phenotype } \\
\hline & $A \cos (a)$ & NON-AE (b) & AE NON-CB (c) & AE CB (d) & $p$-value \\
\hline LAMA (monotherapy) & $0(0.0 \%)$ & $22(8.3 \%)^{d}$ & $3(8.8 \%)$ & I $(0.9 \%)^{b}$ & 0.013 \\
\hline LABA (monotherapy) & $0(0.0 \%)$ & $48(18.1 \%)^{d}$ & $2(5.9 \%)$ & $3(2.8 \%)^{b}$ & $<0.001$ \\
\hline ICS (monotherapy) & $0(0.0 \%)$ & $2(0.8 \%)$ & $0(0.0 \%)$ & $0(0.0 \%)$ & 0.999 \\
\hline LAMA+LABA & 2 (9.1\%) & $54(20.4 \%)^{d}$ & 8 (23.5\%) & $9(8.3 \%)^{b}$ & 0.013 \\
\hline LAMA+ICS & $0(0.0 \%)$ & I (0.4\%) & $0(0.0 \%)$ & $2(1.8 \%)$ & 0.477 \\
\hline LABA+ICS & $6(27.3 \%)$ & 30 (II.3\%) & $2(5.9 \%)$ & $19(17.4 \%)$ & 0.053 \\
\hline LAMA+LABA+ICS & $14(63.6 \%)$ & $96(36.2 \%)^{d}$ & 19 (55.9\%) & $74(67.9 \%)^{b}$ & $<0.001$ \\
\hline LAMA (all regimens) & $16(72.7 \%)$ & $173(65.3 \%)^{c, d}$ & $30(88.2 \%)^{b}$ & $86(78.9 \%)^{b}$ & 0.006 \\
\hline LABA (all regimens) & $22(100 \%)$ & 228 (86\%) & 31 (9I.2\%) & 105 (96.3\%) & 0.15 \\
\hline ICS (all regimens) & $20(90.9 \%)^{b, c}$ & $129(48.7 \%)^{\mathrm{a}, \mathrm{d}}$ & $21(61.8 \%)^{a, d}$ & $95(87.2 \%)^{b, c}$ & $<\mathbf{0 . 0 0 I}$ \\
\hline Mucoactive drugs & $0(0.0 \%)$ & $7(2.6 \%)^{d}$ & $0(0.0 \%)$ & $12(11.0 \%)^{b}$ & 0.359 \\
\hline Roflumilast & $0(0.0 \%)$ & $2(0.8 \%)$ & I (2.9\%) & $0(0.0 \%)$ & 0.384 \\
\hline Antibiotics (long-term or pulsed) & $0(0.0 \%)$ & $0(0.0 \%)$ & $0(0.0 \%)$ & I (0.9\%) & 0.359 \\
\hline
\end{tabular}

Notes: Categorical parameters are described by absolute (relative) frequencies, and statistical significance was determined by the Fisher exact test. Indices a-d indicate a statistical significant difference between two phenotypes (Fisher exact test). Bold represent statistically significant values $(p<0.05)$.

Abbreviations: ACOS, asthma-COPD overlap syndrome; NON-AE, non-exacerbator phenotype; $A E$ NON-CB, frequent exacerbators without chronic bronchitis, predominantly with emphysema; $\mathrm{AE} \mathrm{CB}$, frequent exacerbators with chronic bronchitis; LAMA, long-acting muscarinic antagonists; LABA, long-acting beta agonists; ICS, inhaled corticosteroids. 
exacerbators were patients with clinical features corresponding to chronic bronchitis (75\%). The percentage of patients with the ACOS phenotype was relatively low (5.1\%). Our study also demonstrated that patients with different COPD phenotypes present different disease characteristics in terms of magnitude of symptoms (measured by CAT and mMRC scores), severity of airflow limitation, smoking habit, atopy status, and some comorbidities. Compared to other phenotypes, patients with the AE phenotypes were more symptomatic and had the greatest degree of airway obstruction (based on $\mathrm{FEV}_{1} \%$ of predicted).

Some previous studies have also evaluated the distribution of various COPD phenotypes. Cosio et al found the following distribution of COPD phenotypes when using the definitions found in the Spanish guidelines: non-exacerbator with either chronic bronchitis or emphysema, 66.2\%; ACOS, $15.0 \%$; frequent exacerbator with chronic bronchitis, $11.9 \%$; and frequent exacerbator with emphysema, 4.6\%. ${ }^{17}$ Using a similar definition of phenotypes, Miravitilles et al observed the following frequencies of phenotypes: non-exacerbator, $60.6 \%$; ACOS, 15.9\%; exacerbator with chronic bronchitis, $19.3 \%$; and exacerbator without chronic bronchitis, $4.3 \%{ }^{18}$ The definitions of COPD phenotypes used in the POPE study were similar to, but not exactly the same as, those used in the Spanish guidelines. As such, the distributions of COPD phenotypes in the Polish cohort of POPE study were slightly different to those observed in the studies by Cosio et al and Miravitilles et al. In particular, we found a lower proportion of patients with ACOS in the Polish population ( $5.1 \%$ vs $15 \%$ and $15.9 \%$ in the studies by Cosio et al and Miravitilles et al, respectively) and a higher percentage of frequent exacerbators with chronic bronchitis $(25.3 \%$ vs $11.9 \%$ and $19.3 \%$, respectively). This observation is consistent with the results of the study published by Calle Rubio, which revealed an ACOS prevalence of 6.5\%. ${ }^{23}$ Another study, using modified 2012 Spanish COPD guidelines to define ACOS, found a prevalence of $5 \%$ for the patients with COPD caused by tobacco, ${ }^{24}$ which is similar to the results described in our study.

However, the percentage of patients with ACOS found in our study was significantly lower than the pooled prevalence of ACOS calculated in the meta-analysis by Alshabanat et al. ${ }^{25}$ This may be due to the different criteria used for the diagnosis of ACOS among studies, including the POPE study. Indeed, the exact definition of asthma and COPD overlap remains ambiguous. Even the most recent document developed by the science committee of the Global Initiative for Asthma does not give a definition for ACOS, but instead describes it as a syndrome characterized by persistent airflow limitation with several features usually associated with asthma and several features usually associated with COPD. ${ }^{26}$ Indeed, it has previously been shown how the diagnostic criteria used for ACOS can influence epidemiology. ${ }^{27}$ Meanwhile, in the entire POPE study (in which the diagnostic criteria of ACOS was kept uniform), the distribution of the ACOS phenotype across the different countries had the lowest heterogeneity. ${ }^{22}$ Therefore, more studies using the same diagnostic criteria for ACOS are required to compare the prevalence of ACOS in different countries.

The varying magnitude of environmental pollution, smoking habits, and comorbidities across European populations may also contribute to the observed differences in phenotype distribution. The levels of air pollution are higher in CEE countries than in Western Europe. Poland is unfortunately one of the leaders in poor air quality, and widely exceeds the daily limit for particular matter. ${ }^{28}$ Exposure to ambient air pollution, especially to particulate matter, is a major risk factor for pulmonary diseases such as asthma, chronic bronchitis, or pneumonia. ${ }^{29}$ In the entire POPE study, 63\% of the COPD patients were NON-AE, 20.4\% were $\mathrm{AE} \mathrm{CB}, 9.5 \%$ were $\mathrm{AE}-\mathrm{NON} \mathrm{CB}$, and $6.9 \%$ were ACOS. ${ }^{22}$ The frequencies of particular phenotypes in the Polish cohort were more similar to those observed for all CEE countries participating in the POPE study, which emphasizes the importance of precise phenotype definitions. Furthermore, similar environmental conditions are likely to give congruous observation results. Therefore, taking these factors into account, our percentage of patients with ACOS is not surprisingly low.

Previous studies have shown that the ACOS and CB phenotypes are characterized by the most severe clinical course. In the PLATINO study, asthma and overlap patients were characterized by higher risk of exacerbations and worse general health status. ${ }^{30}$ Similarly, COPD patients with chronic bronchitis had worse lung function and general health status, and had more respiratory symptoms, physical activity limitation, and exacerbations than those with other COPD phenotypes. ${ }^{31}$ In our study, both ACOS and AE CB patients received the highest medication regimens (more than $60 \%$ of subjects on triple therapy), suggesting a more severe disease. However, in terms of symptom load, those with the AE CB phenotype had the worse scores.

Our observations are similar to the results from the French study by Caillaud et al (ie, the "INITIATIVES BronchoPneumopathie Chronique Obstructive" cohort). ${ }^{32}$ This study showed that patients with ACOS suffer more from atopic 
diseases and obesity and use more medication, while disease severity (symptoms, exacerbations, comorbidities) and prognosis (mortality) do not differ from "pure" COPD patients. ${ }^{32}$ Meanwhile, the characteristics of frequent exacerbators with chronic bronchitis are more consistent. Like in our study, Cosio et al found that frequent exacerbators with chronic bronchitis reported more severe symptoms and were treated with more medications than patients with other COPD phenotypes. ${ }^{17}$ Similar observations were made in the COPDGene study: chronic bronchitis was associated with more severe respiratory symptoms and higher risk of exacerbations. ${ }^{33}$

The Polish guidelines for COPD management are strongly based on GOLD strategy and therefore do not indicate a phenotype-based strategy. ${ }^{34} \mathrm{We}$ found differences in the administered medication among phenotypes, which likely reflects some overlap between a phenotype-based treatment approach and treatment based on GOLD classification (as currently recommended). For example, the ACOS and frequent exacerbator phenotypes were expected to have the highest proportions of patients treated with ICS. ICS were recommended by GOLD 2014 for patients with high risk of exacerbations (assessed based on lung function and prior history of exacerbations). ${ }^{1}$ It is known that ACOS patients with features of asthmatic inflammation in the airways especially benefit from ICS therapy. ${ }^{15}$ Nonetheless, not all ACOS and frequent exacerbators received ICS in our study, which to some extent can be explained by the fact that some of the GOLD C and D subjects among frequent exacerbators had $\mathrm{FEV}_{1}$ values $>50 \%$ of predicted. This suggests that physicians may pay too little attention to the asthma and COPD overlap, and the GOLD strategy document should provide more precise diagnostic criteria. Meanwhile, many of the GOLD C and D subjects did receive ICS, although not all of them experienced frequent exacerbations. The reason that the majority of non-frequent exacerbator patients were treated with ICS could be low FEV 1 values, which places them into the GOLD C and D categories. ${ }^{1}$

The abovementioned observations, together with the high use of triple therapy in NON-AE patients (despite current recommendations), suggest that a better strategy for treating patients with COPD is warranted. Therefore, considering a phenotype-based therapeutic strategy for COPD may be more appropriate. Indeed, the new GOLD 2017 strategy document redefines the GOLD A-D categories, ${ }^{2}$ excluding low $\mathrm{FEV}_{1}$ value as a predictor of future exacerbations, thereby making information on symptoms and past exacerbations more crucial. It is possible the percentage of subjects in the GOLD A-D categories will change if $\mathrm{FEV}_{1}$ values are not considered. The updated guidelines also diminish the role of ICS therapy in COPD; therefore, the overuse of ICScontaining treatment in non-exacerbating COPD patients is an important practical observation. It would be interesting to determine whether data from the Polish POPE study cohort, which adhered to the new GOLD strategy document, are comparable to the entire POPE cohort data. ${ }^{35}$

Our study does have some limitations. First, the number of recruited patients was relatively small compared to other population-based epidemiological studies. Second, patients were classified to predefined phenotypes according to a simple algorithm taking into account only symptoms, history of exacerbations, and previous diagnosis of asthma. ${ }^{19}$ We realize that the use of more advanced diagnostic methods (such as induced sputum analysis or computed tomography scanning) would enable more extensive and more precise phenotyping, which may further affect the choice of the most effective therapeutic options. On the other hand, the limited number of phenotypes that were diagnosed based on easily available clinical data may be considered a study advantage, as this approach better fits with real-life clinical practice. Third, it was the interview with the patient and the analysis of available medical documentation that served as the main source of information about any comorbid conditions. Performing additional diagnostics tests or using questionnaires to recognize depressive or anxiety disorders would certainly improve the accuracy of the analysis. Finally, as six of the seven centers recruiting the patients were teaching hospital-based pulmonary departments located in large Polish cities, we cannot exclude some bias in patient selection. These include place of patient residence $(74 \%$ of enrolled patients were residents of urban areas) and selection of patients with more severe disease. Indeed, the proportion of patients with severe disease in outpatient departments of tertiary referral university hospitals is likely higher than in other medical centers. We eagerly await the distribution and characteristics of COPD phenotypes found in sub-cohorts of patients evaluated in other countries.

\section{Conclusion}

This study provides information regarding distribution, clinical presentation, and treatment modalities of predefined COPD phenotypes observed in the Polish population. Further research is needed to evaluate the natural course of COPD phenotypes and whether a phenotype-based approach for the treatment of COPD is associated with better clinical outcomes than current approaches relying on lung function, history of exacerbations, and symptoms. 


\section{Acknowledgments}

The authors would like to thank the staff of all the study centers for their cooperation in collecting the study data. The electronic case report form design and statistical analysis for sample size calculation was performed by Jiri Jarkovsky and Michal Uher (Institute of Biostatistics and Analyses, Faculty of Medicine, Masaryk University, Brno, Czech Republic). The authors are grateful to the POPE study Steering Committee members - Assoc Prof Arschang Valipour (MD, PhD), Prof Neven Tudoric (MD, PhD), Vladimir Koblizek, (MD, PhD), Prof Attila Somfay (MD, PhD), Prof Kirill Zykov (MD, PhD), Prof Ruzena Tkacova (MD, PhD), and Prof Marc Miravitlles (MD, PhD) - for their contribution in the preparation of the study protocol and for the provision and processing of the data involving the Polish sub-cohort of patients. The authors would like to thank Boehringer Ingelheim for the support throughout the study.

\section{Disclosure}

The authors report no conflicts of interest in this work.

\section{References}

1. Travis WD, Costabel U, Hansell DM, et al; ATS/ERS Committee on Idiopathic Interstitial Pneumonias. An official American Thoracic Society/European Respiratory Society Statement: update of the international multidisciplinary classification of the idiopathic interstitial pneumonias. Am J Respir Crit Care Med. 2013;188(6):733-748.

2. Vogelmeier CF, Criner GJ, Martinez FJ, et al. Global strategy for the diagnosis, management, and prevention of chronic obstructive lung disease 2017 report. GOLD executive summary. Eur Respir J. 2017;49(3). pii: 1700214.

3. Barrecheguren M, Esquinas C, Miravitlles M. The asthma-chronic obstructive pulmonary disease overlap syndrome (ACOS): opportunities and challenges. Curr Opin Pulm Med. 2015;21(1):74-79.

4. Gould NS, Min E, Gauthier S, Chu HW, Marti R, Day BJ. Aging adversely affects the cigarette smoke-induced glutathione adaptive response in the lung. Am J Respir Crit Care Med. 2010;182(9):1114-1122.

5. Matkovic Z, Tudoric N, Miravitlles M. Impact of chronic bronchial infection in the lung and beyond. Eur Respir Mon. 2013;60:46-57.

6. Weiss ST. What genes tell us about the pathogenesis of asthma and chronic obstructive pulmonary disease. Am J Respir Crit Care Med. 2010;181(11):1170-1173.

7. Torres-Duque C, Maldonado D, Pérez-Padilla R, Ezzati M, Viegi G; Forum of International Respiratory Studies (FIRS) Task Force on Health Effects of Biomass Exposure. Biomass fuels and respiratory diseases: a review of the evidence. Proc Am Thorac Soc. 2008;5(5):577-590.

8. Hnizdo E, Sullivan PA, Bang KM, Wagner G. Association between chronic obstructive pulmonary disease and employment by industry and occupation in the US population: a study of data from the Third National Health and Nutrition Examination Survey. Am J Epidemiol. 2002;156(8): 738-746.

9. Koblizek V, Chlumsky J, Zindr V, et al; Czech Pneumological and Phthisiological Society. Chronic obstructive pulmonary disease: official diagnosis and treatment guidelines of the Czech Pneumological and Phthisiological Society; a novel phenotypic approach to COPD with patient-oriented care. Biomed Pap Med Fac Univ Palacky Olomouc Czech Repub. 2013;157(2):189-201.

10. Han MK, Agusti A, Calverley PM, et al. Chronic obstructive pulmonary disease phenotypes: the future of COPD. Am J Respir Crit Care Med. 2010;182(5):598-604.
11. Miravitlles M, Soler-Cataluña JJ, Calle M, et al. Spanish COPD guidelines (GesEPOC) 2017. Pharmacological treatment of stable chronic obstructive pulmonary disease. Arch Bronconeumol. 2017;53(6): 324-335.

12. Miravitlles M, Soler-Cataluña JJ, Calle M, Soriano JB. Treatment of COPD by clinical phenotypes: putting old evidence into clinical practice. Eur Respir J. 2013;41(6):1252-1256.

13. Zhong N, Wang C, Zhou X, et al. LANTERN: a randomized study of QVA149 versus salmeterol/fluticasone combination in patients with COPD. Int J Chron Obstruct Pulmon Dis. 2015;10(1):1015-1026.

14. Rossi A, Guerriero M, Corrado A; OPTIMO/AIPO Study Group. Withdrawal of inhaled corticosteroids can be safe in COPD patients at low risk of exacerbation: a real-life study on the appropriateness of treatment in moderate COPD patients (OPTIMO). Respir Res. 2014;15(1):77.

15. Gershon AS, Campitelli MA, Croxford R, et al. Combination longacting $\beta$-agonists and inhaled corticosteroids compared with long-acting $\beta$-agonists alone in older adults with chronic obstructive pulmonary disease. JAMA. 2014;312(11):1114-1121.

16. Rennard SI, Calverley PM, Goehring UM, Bredenbröker D, Martinez FJ. Reduction of exacerbations by the PDE4 inhibitor roflumilast - the importance of defining different subsets of patients with COPD. Respir Res. 2011;12(1):18.

17. Cosio BG, Soriano JB, López-Campos JL, et al; CHAIN Study. Distribution and outcomes of a phenotype based approach to guide COPD management: results from the CHAIN cohort. PLoS One. 2016; 11(9):e0160770.

18. Miravitlles M, Barrecheguren M, Román-Rodríguez M. Frequency and characteristics of different clinical phenotypes of chronic obstructive pulmonary disease. Int J Tuberc Lung Dis. 2015;19(8):992-998.

19. Zbozinkova Z, Barczyk A, Tkacova R, et al. POPE study: rationale and methodology of a study to phenotype patients with COPD in Central and Eastern Europe. Int J Chron Obstruct Pulmon Dis. 2016;11(1): 611-622.

20. Bestall JC, Paul EA, Garrod R, Garnham R, Jones PW, Wedzicha JA. Usefulness of the Medical Research Council (MRC) dyspnoea scale as a measure of disability in patients with chronic obstructive pulmonary disease. Thorax. 1999;54(7):581-586.

21. Jones PW, Harding G, Berry P, Wiklund I, Chen WH, Kline Leidy N. Development and first validation of the COPD assessment test. Eur Respir J. 2009;34(3):648-654.

22. Koblizek V, Milenkovic B, Barczyk A, et al. Phenotypes of COPD patients with a smoking history in Central and Eastern Europe: the POPE study. Eur Respir J. 2017;49(5). pii: 1601446.

23. Calle Rubio M, Casamor R, Miravitlles M. Identification and distribution of COPD phenotypes in clinical practice according to Spanish COPD Guidelines: the FENEPOC study. Int J Chron Obstruct Pulmon Dis. 2017;12:2373-2383.

24. Golpe R, Sanjuán López P, Cano Jiménez E, Castro Añón O, Pérez de Llano LA. Distribution of clinical phenotypes in patients with chronic obstructive pulmonary disease caused by biomass and tobacco smoke. Arch Bronconeumol. 2014;50(8):318-324. [Spanish with English abstract].

25. Alshabanat A, Zafari Z, Albanyan O, Dairi M, FitzGerald JM. Asthma and COPD overlap syndrome (ACOS): a systematic review and meta analysis. PLoS One. 2015;10(9):e0136065.

26. The Global Strategy for Asthma Management and Prevention, Global Initiative for Asthma (GINA) 2014. Available from: http://www. ginasthma.org/. Accessed September 27, 2017.

27. Barrecheguren M, Esquinas C, Miravitlles M. The asthma-COPD overlap syndrome: a new entity? COPD Res Pract. 2015;1:8.

28. European Environment Agency Report No 5/2014. Available from: http://www.eea.europa.eu/publications/air-quality-in-europe-2014. Accessed September 27, 2017.

29. Chen BH, Kan HD. Air pollution and population health: a global challenge. Environ Health Prev Med. 2008;13(2):94-101.

30. Menezes AM, Montes de OM, Pérez-Padilla R, et al. Increased risk of exacerbation and hospitalization in subjects with an overlap phenotype: COPD-asthma. Chest. 2014;145(2):297-304. 
31. de Oca MM, Halbert RJ, Lopez MV, et al. The chronic bronchitis phenotype in subjects with and without COPD: the PLATINO study. Eur Respir J. 2012;40(1):28-36.

32. Caillaud D, Chanez P, Escamilla R, et al; Initiatives BPCO scientific committee and investigators. Asthma-COPD overlap syndrome (ACOS) vs "pure" COPD: a distinct phenotype? Allergy. 2017;72(1):137-145.

33. Kim V, Han MK, Vance GB, et al; COPDGene Investigators. The chronic bronchitic phenotype of COPD: an analysis of the COPDGene Study. Chest. 2011;140(3):626-633.
34. Sliwiński P, Górecka D, Jassem E, Pierzchała W. [Polish respiratory society guidelines for chronic obstructive pulmonary disease]. Pneumonol Alergol Pol. 2014;82(3):227-263. [Polish with English abstract].

35. Tudoric N, Koblizek V, Miravitlles M, et al. GOLD 2017 on the way to phenotypic approach? Analysis from the phenotypes of COPD in Central and Eastern Europe (POPE) cohort. Eur Respir J. 2017;49(4): 1602518.

\section{Publish your work in this journal}

The International Journal of COPD is an international, peer-reviewed journal of therapeutics and pharmacology focusing on concise rapid reporting of clinical studies and reviews in COPD. Special focus is given to the pathophysiological processes underlying the disease, intervention programs, patient focused education, and self management protocols.

\section{Dovepress}

This journal is indexed on PubMed Central, MedLine and CAS. The manuscript management system is completely online and includes a very quick and fair peer-review system, which is all easy to use. Visit http://www.dovepress.com/testimonials.php to read real quotes from published authors.

Submit your manuscript here: http://www.dovepress.com/international-journal-of-chronic-obstructive-pulmonary-disease-journal 